\title{
La encuesta como interacción social. Una aproximación empirica
}

\author{
Julián Atienza Aledo \\ Área Investigación, S.A. \\ Francisco JaVier Noya Miranda \\ UNED
}

\section{INTRODUCCIÓN}

El presente trabajo se ocupa de un aspecto de la entrevista personal estandarizada de la encuesta: su dimensión de interacción social. La peculiaridad de este instrumento de medida está en que pretende emular artificialmente una situación comunicativa cotidiana. Las dos personas que interactúan durante la entrevista personal representan unos roles específicos como actores en un intercambio: el entrevistador representa al investigador y el encuestado es el portador de datos -atributos/propiedades/variables- que pueden ser objeto de estudio. Utilizando una analogía procedente de las matemáticas, la obtención de datos científicosociales se basa en una ecuación con varias incógnitas: el sujeto receptor de datos (investigador/entrevistador) y el sujeto oferente de datos (encuestado). Pero además tenemos que hay una interacción entre ambas variables de carácter social, que también hay que despejar.

En la interacción social que se produce en la entrevista ocupa un lugar privilegiado la percepción que tienen los actores tanto los unos de los otros -el encuestador del encuestado y el encuestado del encuestador- como de la situación de la entrevista. La hipótesis de la reactividad sostiene que esas definiciones de la situación repercuten sobre las respuestas del entrevistado introduciendo un sesgo. Esa realidad social generada por la encuesta y los trastornos que introduce en la medición del valor de verdad de las actitudes en principio se pueden estudiar mediante otra encuesta posterior realizada a los encuestados y los encuestadores.

Nos encontramos ante una problemática específica de este método científicosocial (Pawson, 1996). Lamentablemente este aspecto de la encuesta ha sido descuidado por los metodólogos españoles, que sin embargo sí han estudiado otros 
aspectos sociales de la encuesta. Así, García Ferrando/ García (1976) y, más tarde, Justel (1981), recogían la opinión de los encuestados sobre las encuestas en distintos aspectos digamos «macro» (confianza en los resultados, representatividad, utilidad de las encuestas, etc.). Frente a los trabajos de estos autores, nuestro énfasis, en el marco del enfoque de la reactividad, es exclusivamente «micro». Nos interesa esa realidad social 'sui generis' de la entrevista de la encuesta sociológica.

En el trabajo vamos a discutir la hipótesis de la reactividad y a presentar los primeros resultados de una encuesta sobre la encuesta realizada según sus presupuestos. Para ello, seguimos el siguiente orden de exposición. En primer lugar presentamos los argumentos sobre la reactividad y la interacción en la situación de encuesta. A continuación entramos a exponer la metodología de recolección y los datos resultantes. El resto del trabajo contiene el núcleo sustantivo del mismo. Comenzamos con la percepción del encuestador sobre el encuestado en sus distintas dimensiones: la capacidad cognoscitiva del encuestado, su actitud de cooperación, y su motivación de respuesta. Sigue la valoración que tanto el encuestador como el encuestado hacen del ambiente durante la entrevista. Finalmente se conluye con la percepción del encuestador por parte del encuestado.

\section{CONCEPTOS Y ARGUMENTOS}

Tres son las fuentes de sesgo en la encuesta, que se corresponden con sus tres componentes: el encuestador, el encuestado y el cuestionario (efectos de contexto) ${ }^{1}$. En la situación de la entrevista de la encuesta hay que prestar atención a las dos primeras variables: el encuestador y el encuestado.

Del lado del encuestado se ha tratado abundantemente los rasgos de la personalidad, como la aquiescencia, o la deseabilidad social, el efecto más estudiado (Hartmann, 1991).

Además es conocido el efecto del encuestador: el encuestado reacciona ante rasgos del encuestador. Estos pueden ser signos visibles, como el sexo, la edad, la raza o el status; o signos invisibles, como la experiencia o el estilo de hacer la entrevista, en el que entran cogniciones y emociones del entrevistador (Esbensen/ Menard, 1991). Reinecke/ Schmidt (1993) estudiaron el efecto de signos externos del entrevistador, como el status social y la edad en una encuesta sobre actitudes ante los extranjeros, encontrando un efecto negativo del status: a mayor status percibido del encuestador, menor xenofobia del encuestado; y un efecto positivo de la edad: a mayor edad del encuestador, mayor xenofobia del encuestado. Habría además una interacción del efecto del entrevistador con la propensión a responder por deseabilidad social del encuestado. Así, en los menos tendentes a buscar la aprobación social, los jóvenes, la edad del entrevistador no era relevante, aunque

\footnotetext{
1 Ver los trabajos de Esser para un enfoque teórico general sobre estos sesgos desde la teoría de la elección racional. En concreto, sobre los llamados efectos de contexto en el cuestionario, se puede ver también Noya (1998).
} 
sí su status: a mayor status percibido, menor xenofobia. En los encuestados más propensos a dar respuestas socialmente deseables, los mayores, el status del entrevistado no tenía efecto en la respuesta, pero sí su edad, de manera que cuanto mayor era el entrevistador, más propensión a la xenofobia.

En lo tocante a los signos invisibles, Dijkstra (1987) ha mostrado como los entrevistadores que practican un estilo más informal obtienen respuestas más exactas y relevantes a las preguntas. Ello sería así porque el entrevistado está más motivado a participar, al integrarse más fácilmente en la conversación de la entrevista. La constatación de este hecho pone en cuestión la hipótesis alternativa sobre el efecto negativo del estilo informal, según la cual el encuestado, al querer caer en gracia y buscar la camaradería del encuestado, daría respuestas menos relevantes y más acordes a lo socialmente deseable ${ }^{2}$.

Pero, además de los efectos del entrevistado y del entrevistador, hay que tener en cuenta el efecto de la interacción social comunicativa en la entrevista. Las reglas de intercambio social explican en muchos casos la no respuesta (Goyder, 1987). Por otro lado, la pragmática de la conversación también en parte explica los efectos de contexto a los que aludíamos antes ${ }^{3}$. Finalmente, hay que considerar el aspecto socio-psicológico: la reactividad en la interacción social misma entre el entrevistador y el entrevistado ${ }^{4}$. Steinert (1984), en el Instituto Gallup de Viena, y Scholl (1993), posteriormente, han abordado el fenómeno.

La interacción es un rasgo constitutivo de la encuesta personal como método de recolección de datos. El contexto mismo de la entrevista, entendida como una interacción entre el encuestador y el encuestado, es fuente de sesgos.

«el entrevistado en presencia del entrevistador reacciona de forma distinta a lo que lo haría si este no estuviese, o a como lo haría en otras interacciones sociales» (Scholl, 1993: 68).

Hay un efecto propiamente contextual, debido a la situación de la entrevista: lo que se siente que se debe hacer en función de como se interpreta una situación, incluyendo en ésta a las personas que intervienen en ella.

En este fenómeno son centrales las percepciones recíprocas de los dos actores: el entrevistado reacciona ante la impresión que le causa el entrevistador, que a su vez se habrá formado una impresión del entrevistado; ésta influirá sobre su comportamiento en la entrevista, y, consecuentemente, sobre cómo le perciba el entrevistado, etc. Como en cualquier otra forma de interacción esporádica y no conti-

2 En nuestro país sólo contamos con el trabajo de Alvira/ Martínez (1985). Estos autores descubrian que efectivamente la ideología del entrevistador afectaba las respuestas de los entrevistados a una encuesta de actitudes políticas, introduciendo sesgos significativos en los resultados. Sin embargo no se entraba a explicar la raíz de este sesgo.

${ }^{3}$ Esta dimensión de la interacción ha sido más abordada en los estudios sobre la entrevista semiabierta y la entrevista en profundidad. Ver al respecto los trabajos de Briggs (1989) y Mishler (1986)

4 Un último aspecto a considerar, posterior a la interacción en sí, es el efecto que puede tener la entrevista sobre el entrevistado, por ejemplo, clarificando sus opiniones sobre el tema de la encuesta, haciéndolas más consistentes, o llevándole incluso a cambiar de opinión. Sobre este tipo de efectos, en este caso de las entrevistas semiestructuradas, ver Procter/ Padfield (1998). 
nuada, en la que los actores no se conocen, el 'impression management' (la manipulación de las impresiones) y la presentación en público de los actores juega un papel importante en la encuesta. El actor debe elegir entre distintas formas de presentarse en la situación de entrevista en función de la percepción que tiene del otro, que éste también intentará manipular. Pero la necesidad de esas estrategias y la importancia de las imágenes recíprocas es aún más importante en la entrevista de encuesta. En una situación cotidiana se puede intentar evitar un tema que resulte embarazoso o incómodo en la conversación; en la encuesta, por contra, el entrevistador está obligado a preguntar, y el entrevistado se siente obligado a responder. En este sentido, dada esa sobregeneralización de los sentimientos de obligación, el fuego cruzado de espejismos que es la interacción se agudiza en la entrevista de la encuesta (Scholl, 1993: 180).

La situación de la encuesta es en este aspecto doblemente contingente, pues ambas partes actúan y perciben (Scholl, 168). La hipótesis de la reactividad se nutre de la idea de que esta doble contingencia introduce sesgos en las respuestas: por ejemplo, si el encuestado se siente cohibido o amenazado por el entrevistado al haberse formado una determinada imagen de él.

En consonancia con esta hipótesis, Steinert llega a defender la necesidad de practicar un tipo de muestreo situacional ('situations-sampling'). No hay una muestra de personas en la que se obtiene la "opinión auténtica», sino que se confecciona una muestra de situaciones y se establecen patrones de respuesta típicos en función de cada una de ellas.

Empíricamente, la reactividad sociopsicológica en la entrevista se puede abordar de dos maneras. La comunicación no verbal sólo puede captarse mediante la observación. Las cogniciones, actitudes y emociones que se activan durante la entrevista en reacción a las cogniciones, actitudes y emociones que se perciben en el otro participante pueden obtenerse a posteriori mediante una encuesta sobre la encuesta realizada a ambas partes.

El objetivo principal del diseño es conseguir información añadida sobre la entrevista principal, sobre la validez de sus resultados y, sobre la dificultad de la misma. Se invita al encuestado y al encuestador a reflexionar sobre la entrevista que acaban de hacer, al autoaplicarse un cuestionario. Se obtienen así comentarios subjetivos $\mathrm{e}$ indirectos que permiten entender mejor las preguntas del encuestador y las respuestas del encuestado al cuestionario principal. Ello ofrece la posibilidad de relacionar los datos de la encuesta principal con la encuesta metodológica y, de esta forna, tener una imagen más completa de los entrevistados, tanto a la luz de sus actitudes como de su «rectividad» al encuestador.

Mediante este segundo método Scholl, sin embargo, no descubrió reactividad alguna de las respuestas a las actitudes del entrevistador o a la situación de la entrevista. La valoración del encuestado sobre el encuestador no estaba asociada significativamente a los patrones de respuesta.

Con todo, es aún más interesante que Scholl encuentra una radical independencia en las percepciones recíprocas del entrevistador y el entrevistado. Así, por ejemplo, respecto a un mismo tema, el humor del entrevistado antes y después de la entrevista, la valoración del encuestador y la del encuestado podían ser completamente contradictorias. 
Por su parte, Reinecke encuentra una correspondencia sólo moderada. Los entrevistados que obtuvieron unas puntuaciones más bajas en la escala de deseabilidad social fueron percibidos por el encuestador como personas más seguras de sí mismas que las que puntuaron más alto en la escala (Reinecke, 1991: 229).

La falsación de la hipótesis de la reactividad pudiera obedecer a problemas metodologicos, es decir, al método elegido para contrastarla. Scholl argumenta que la hipótesis de la reactividad de la encuesta no supera la contrastación empírica por los problemas que genera el hecho de realizar el test mediante otra encuesta. La valoración que el encuestado hace del encuestador es siempre muy benévola, sin variar apenas. Seguramente el encuestado cree que así evita problemas al encuestador. Quizás el encuestado atribuye la incomodidad que le pueda haber producido la encuesta al cuestionario, y no al entrevistador (Scholl, 1993: 295). La encuesta no serviría entonces para estudiar la encuesta, por el círculo vicioso de representaciones y expectativas que genera.

En cualquier caso, la ausencia del nexo causal entre el «impression management» en la entrevista y las respuestas a la encuesta hacen que el interés de la investigación sea más descriptivo que explicativo: radica en poder elaborar tipologías de las situaciones de entrevista (Scholl, 1993: 298), que acaso podrán servir para ir hacia un muestreo de tipo situacional como el propuesto por Steinert.

En línea con los planteamientos de Scholl nos vamos a limitar a la descripción de las imágenes recíprocas que se desprenden de la encuestas, y a comparar los resultados obtenidos en España con los producidos en Alemania.

\section{DATOS}

En el diseño de la investigación y de los cuestionarios se ha intentado replicar el utilizado por Scholl (1993) en Alemania. El resultado son los datos del estudio 2.189 del Centro de Investigaciones Sociológicas. Para él se realizaron tres encuestas: dos al encuestado y una al encuestador.

El cuestionario principal, es decir, aquel cuestionario que aplica directamente, leyendo las preguntas, al entrevistado, trata de la escala de deseabilidad social y la escala de autoritarismo y, no se va a analizar en el presente trabajo.

El cuestionario del entrevistador es autoadministrado y se aplica después de cada entrevista realizada. En un primer bloque de preguntas debe valorar a través del diferencial semántico las distintas características y actitudes del encuestado ante la encuesta. Para ello se utiliza una escala de diez puntos, en el cual, por norma general, está a la izquierda la valoración negativa (codificada con el valor 1), y a la derecha la valoración positiva (codificada con el valor 10). El número de entrevistadores fue de 20.

El cuestionario del encuestado también es autoadministrado y se autoaplica una vez realizada la entrevista. La cuota de respuesta se situó en un $53 \%$ $(\mathrm{N}=315)$ sobre la muestra total $(\mathrm{N}=597)$, ya que se trataba de una colaboración absolutamente voluntaria por parte del encuestado. En este cuestionario también se ha utilizado el diferencial semántico con una escala de 10 puntos. 


\section{LA CAPACIDAD COGNITIVA DEL ENCUESTADO EN LA PERCEPCIÓN DEL ENCUESTADOR}

\subsection{Descripción de las variables}

El éxito de una entrevista no depende sólo de su realización, sino también de la calidad concreta de los datos que se producen/construyen durante el transcurso de la misma. Para entender mejor esta situación dinámica se ha preguntado directamente a los encuestadores por su impresión de sus entrevistas. Ellos han valorado a cada uno de "sus» encuestados, utilizando una escala de diez puntos referida a lo bien que han entendido las preguntas y a la capacidad cognitiva de la que disponían.

Scholl define las siguientes dimensiones (ver tabla 1):

a) la comprensión concreta de las preguntas(ítem 1 y 2),

b) la capacidad cognitiva general (ítem 3,4 y 5),

c) el componente motivacional (interés) (ítem 6,7 y 8 ) y

d) el componente de interacción (comportamiento) (ítem 9 y 10).

TABLA 1

Percepción de la comprensión de las preguntas y la capacidad cognoscitiva de los encuestados

\begin{tabular}{lcccc}
\hline Ítem: «El encuestado...» & & Media & S.D. & (N) \\
\hline No entiende/entiende las preguntas & (a) & 7,68 & 2,11 & 597 \\
No/si diferencia entre información y opinión & (a) & 7,63 & 2,14 & 597 \\
No/si parece saber de temas políticos & (b) & 6,53 & 2,38 & 597 \\
Es ignorante/inteligente & (b) & 7,02 & 2,04 & 596 \\
Se expresa muy mal/bien & (b) & 7,35 & 1,89 & 597 \\
Es superficial/meticuloso & (c) & 6,82 & 1,95 & 597 \\
Es desinteresado/interesado & (c) & 4,85 & 2,71 & 597 \\
Es distraído/atento & (c) & 7,78 & 1,89 & 597 \\
Parece una persona insegura/segura & (d) & 7,41 & 2,04 & 597 \\
Necesita/no necesita ayuda para responder & (d) & 7,86 & 2,3 & 597 \\
\hline
\end{tabular}

Casi todos los ítems muestran una inclinación hacia la derecha, es decir, la media está más cerca del valor 10 que del valor 1 . Asimismo, las desviaciones típicas de los ítems reflejan un parecido grado de dispersión. La única excepción es una de las dos categorías que apuntan hacia la dimensión motivacional: el encuestado parece estar más desinteresado que interesado, según del encuestador. Esta percepción anómala, en comparación con el resto de los ítems, podría ser causada por un significado ambivalente de la misma categoría de respuesta -(desinteresado/interesado respecto a qué: ¿la entrevista?, ¿en general?)-, o 
debida más al desinterés que al interés real, dado que en el cuestionario principal no se les pregunta por su opinión sobre temas de actualidad.

Por lo tanto, se puede constatar de que el encuestador percibe que el encuestado es más racional que irracional, reconociendo de esta forma su complejidad cognitiva. Se diría que, de antemano, el encuestador no alberga prejuicios sobre el encuestado, y que tiende a percibirlo positivamente.

\subsection{Dimensiones de la complejidad cognoscitiva}

Todas las variables descritas anteriormente se someten a un análisis factorial -análisis de componentes principales- para resumirlas y reducirlas a nuevas dimensiones independientes. Excluimos el ítem desinteresado/interesado debido a su posible significado ambivalente. El resultado muestra una estructura de unidimensional (ver tabla 2). El factor explica el 61,9\% de la varianza de los ítems. Los elevados pesos factoriales reafirman la coherencia interna de las percepciones y los juicios de los encuestadores sobre la compleja capacidad cognoscitiva de los encuestados, definida anteriormente en cuatro dimensiones conceptuales -comprensión concreta de las preguntas, cognición general, motivación e interacción.

\section{TABLA 2}

Análisis de componentes principales «de la capacidad cognoscitiva del encuestado» $(\mathrm{N}=596)$

\begin{tabular}{llc}
\hline Ítem: «El encuestado...» & & Factor 1 \\
\hline No entiende/entiende las preguntas & (a) 0,84639 \\
No/si diferencia entre información y opinión & (a) 0,85998 \\
No/si parece saber de temas políticos & (b) 0,69632 \\
Es ignorante/inteligente & (b) 0,84424 \\
Se expresa muy mal/bien & (b) 0,89833 \\
Es superficial/meticuloso & (c) 0,61832 \\
Es distraído/atento & (c) 0,74311 \\
Parece una persona insegura/segura & (d) 0,76007 \\
Necesita/no necesita ayuda para responder & (d) 0,77116 \\
\hline
\end{tabular}

\subsection{Tipología de los encuestados según su complejidad cognoscitiva}

El procedimiento elegido para definir una tipología ha sido el análisis de conglomerados. El planteamiento es el inverso al análisis de componentes principales: si éste último agrupa los individuos reduciendo la complejidad de la constelación de las variables, obteniendo de esta forma nuevas dimensiones/factores, el análisis de conglomerados selecciona y agrupa a las personas según esta constelación inicial de las variables, permitiendo así la formación de tipos. 
En concreto, se ha elegido un análisis de conglomerados no jerárquico y partitivo, en el que se define inicialmente el número de clusters y el algoritmo iterativo asigna todos los individuos de la muestra a un conglomerado, según su menor distancia al centroide del mismo. La iteración permite tener al final homogeneidad intracluster (las distancias de las personas que pertenecen al conglomerado son las mínimas posibles) y heterogeneidad entre los clusters (las distancias de los individuos que pertenecen al cluster A son máximas respecto al cluster B). Esta técnica de análisis es exploratoria y requiere estudiar tipologías de dos, tres, cuatro o más grupos.

En este caso la solución óptima es la tipología formada por tres grupos que reflejan las siguientes características:

Cluster A. (Cognición alta). Es el grupo de mayor tamaño (47\%). Se trata de individuos altamente competentes para la realización de entrevistas, reflejando una elevada capacidad cognoscitiva. Las respuestas a los ítems seleccionados puntúan muy por encima de la media (ver tabla 3 ).

Cluster B. (Cognición media) Es un conglomerado de individuos, también de elevado tamaño muestral (41\%), que puntúa en los items por encima de la media. Tienen una menor capacidad cognoscitiva, pero tampoco deberían causar problemas en entrevistas estandarizadas.

Cluster C. (Cognición baja) Es un cluster de personas cuyas contestaciones reflejan valores que están ligeramente por debajo de las medias. Se trata de aquellos encuestados en los que el encuestador percibe una competencia menor, y que han podido contestar al cuestionario principal con cierta imprecisión. De todas formas es un grupo claramente minoritario entre los encuestados (13\%).

TABLA 3

Tipología de la complejidad cognoscitiva

\begin{tabular}{lcccc}
\hline Item: «El encuestado...» & $\begin{array}{c}\text { Total } \\
(\mathbf{N = 5 9 7 )} \\
\mathbf{1 0 0 \%}\end{array}$ & $\begin{array}{c}\text { Cluster A } \\
(\mathbf{N = 2 7 7 )} \\
\mathbf{4 6 , 6 \%}\end{array}$ & $\begin{array}{c}\text { Cluster B } \\
(\mathbf{N = 2 4 3 )} \\
\mathbf{4 0 , 7 \%}\end{array}$ & $\begin{array}{c}\text { Cluster C } \\
(\mathbf{N = 7 6 )} \\
\mathbf{1 2 , 7 \%}\end{array}$ \\
\hline No entiende/entiende las preguntas & 7,68 & 9,06 & 7,27 & 3,95 \\
No/si diferencia entre información y opinión & 7,63 & 9,17 & 7,00 & 4,03 \\
No/si parece saber de temas políticos & 6,53 & 7,99 & 5,77 & 3,59 \\
Es ignorante/inteligente & 7,02 & 8,56 & 6,16 & 4,17 \\
Se expresa muy mal/bien & 7,35 & 8,78 & 6,68 & 4,29 \\
Es superficial/meticuloso & 6,82 & 7,91 & 6,13 & 5,09 \\
Es distraído/atento & 7,78 & 9,01 & 7,07 & 5,47 \\
Parece una persona insegura/segura & 7,41 & 8,81 & 6,60 & 4,90 \\
Necesita/no necesita ayuda para responder & 7,86 & 9,28 & 7,42 & 4,08 \\
\hline
\end{tabular}

El análisis discriminante, cuyos resultados no mostramos aquí, ha corroborado esta estructura de la población. 
Como es sabido, el análisis de conglomerados se puede utilizar para estudiar perfiles cualitativos entre clusters. Podríamos saber, por ejemplo, si la estructura de edades del cluster de cognición alta es sustancialmente distinto al cluster de cognición baja. Pero la presente aplicación de dicho análisis sólo pretende identificar el aspecto cuantitativo -el tamaño muestral de un cluster-y su comportamiento respecto a los ítems estudiados.

\section{LA ACTITUD DE COOPERACIÓN DEL ENCUESTADO EN LA PERCEPCIÓN DEL ENCUESTADOR}

\subsection{Descripción de las variables}

Otro aspecto imprescindible para la realización correcta de una entrevista es la cooperación del encuestado, que se manifiesta en la disponibilidad a responder o no a las preguntas procedentes de un cuestionario estandarizado. Para explicar este comportamiento hay que traer a un primer plano las disposiciones latentes del encuestado, determinantes en la interacción social durante el transcurso de la entrevista. Las impresiones sobre la cooperación del encuestador se miden en el cuestionario con cuatro items (ver tabla 4).

\section{TABLA 4}

El comportamiento de cooperación de los encuestados

\begin{tabular}{lccc}
\hline ftem: $\star$ El encuestado...* & Media & S.D. & (N) \\
\hline Es callado/hablador & 6,20 & 2,21 & 597 \\
Responde de mala gana/gustosamente & 7,82 & 2,00 & 597 \\
Es impaciente/paciente & 7,49 & 2,22 & 596 \\
Esta a la defensiva/dispuesto a informar & 7,86 & 2,10 & 596 \\
\hline
\end{tabular}

Claramente se observa una tendencia hacia la derecha en la escala de diez puntos. Por lo tanto, se percibe un buen grado de cooperación de los encuestados.

\subsection{Dimensiones de las variables}

Como ya procedimos anteriormente respecto a la capacidad cognoscitiva, el segundo paso es reducir los ítems de disposición a la cooperación en dimensiones. De la tabla 5 se deduce que las cuatro respuestas se resumen en un único factor que explica el $66 \%$ de la varianza. Los pesos factoriales son máximos en aquellas variables que se refieren al comportamiento de respuesta a las preguntas de si «responde con mala gana/gustosamente» y «está a la defensiva/dispuesto a informar». En cambio, el item "callado/hablador» tiene el peso factorial menor, lo que resulta plausible, ya que no se refiere al comportamiento de respuesta, sino a un rasgo general de la personalidad. 
TABLA 5

Análisis de componentes principales del comportamiento de cooperación de los encuestados $(\mathbf{N}=596)$

\begin{tabular}{ll}
\hline Item: «El encuestado...» & Factor $\mathbf{1}$ \\
\hline Es callado/hablador & 0,59276 \\
Responde de mala gana/gustosamente & 0,91052 \\
Es impaciente/paciente & 0,79864 \\
Esta a la defensiva/dispuesto a informar & 0,90218 \\
\hline
\end{tabular}

\subsection{Tipología de los encuestados según su actitud de cooperación}

Aplicando de nuevo el análisis de conglomerados, la percepción del encuestador sobre la colaboración cristaliza nítidamente en dos clusters (ver tabla 6). El grupo cuantitativamente más númeroso (69\%) -cluster A, de cooperadores- muestra una buena disponibilidad para cooperar en la entrevista, mientras el cluster B de resistentes (31\%) refleja un comportamiento neutro: los ítems tienen unas medias muy cercanas a la media de la escala de 10. En cualquier caso no emerge un grupo cuantitativamente grande que refleje unos valores que den a entender una falta de disponibilidad a la realización de la entrevista.

\section{TABLA 6}

Tipología del comportamiento de cooperación de los encuestados durante la entrevista

\begin{tabular}{lccc}
\hline ftem: «El encuestado...* & $\begin{array}{c}\text { Total } \\
(\mathbf{N = 5 9 7 )} \\
\mathbf{1 0 0 \%}\end{array}$ & $\begin{array}{c}\text { Cluster A } \\
(\mathbf{N = 4 1 0 )} \\
\mathbf{6 8 , 7 \%}\end{array}$ & $\begin{array}{c}\text { Cluster B } \\
(\mathbf{N = 1 8 6})\end{array}$ \\
\hline Es callado/hablador & $\mathbf{6 , 2 0}$ & 6,76 & 4,96 \\
Responde de mala gana/gustosamente & 7,82 & 8,80 & 5,66 \\
Es impaciente/paciente & 7,49 & 8,52 & 5,23 \\
Esta a la defensiva/dispuesto a informar & 7,86 & 8,93 & 5,50 \\
\hline
\end{tabular}

\section{VALORACIÓN DEL ENCUESTADOR SOBRE LA MOTIVACIÓN DE RESPUESTA DEL ENCUESTADO Y MODO DE INTERACCIÓN}

\subsection{Descripción de las variables}

Los aspectos motivacionales sólo se han indagado a través del cuestionario de los encuestadores, debido a que las personas entrevistadas no dirían, $a$ 
posteriori, la verdad sobre las respuestas no sinceras. Por este motivo, sólo los entrevistadores han estimado la calidad de las respuestas y su base motivacional. La tabla 7 muestra diáfanamente una tendencia a la valoración postiva: todos los ítems estan por encima de la media, inclinándose la moda hacia la derecha. Destacan, en dicha tendencia, el grado de sinceridad y de amabilidad.

TABLA 7

Percepción del entrevistador sobre el modo de interacción

\begin{tabular}{lccc}
\hline f́tem: «El encuestado...» & Media & S.D. & (N) \\
\hline Responde contradictoriamente/coherentemente & 7,60 & 2,04 & 596 \\
Responde con poca/mucha sinceridad & 8,18 & 1,78 & 597 \\
Se esfuerza/le da igual en quedar bien & 5,84 & 2,71 & 597 \\
Tiene un carácter cerrado/abierto & 6,93 & 2,28 & 597 \\
Es grosero/amable & 8,28 & 1,63 & 597 \\
Parece una persona antipática/simpática & 7,89 & 1,76 & 597 \\
Es callado/hablador & 6,20 & 2,21 & 597 \\
Ha sido díficil/fácil de entrevistar & 7,79 & 2,14 & 596 \\
Tuvo una actitud recelosa/despreocupada & 7,45 & 2,20 & 597 \\
Ha sido sumiso/dominante & 5,51 & 1,63 & 597 \\
Ha sido atrevido-arrogante/comedido-prudente & 6,74 & 1,94 & 597 \\
\hline
\end{tabular}

\subsection{Dimensiones de la motivacón de respuesta y del modo de interacción}

Con la ayuda del análisis de componentes principales vamos a indagar en las estructuras latentes de los ítems mencionados. Excluyendo la categoría se esfuerza en quedar bien/le daba igual quedar bien se logra la solución de dos factores más óptima (ver tabla 8). En la primera dimensión se mezclan, con elevadas cargas factoriales, los items que describen tanto aspectos concretos de la interacción (persona antipática/simpática, actitud recelosa/despreocupada, etc.) como valoraciones cualitativas de las respuestas (responde con poca/mucha sinceridad, responde contradictoriamente/coherentemente, etc.). Por lo tanto, este factor, en el cual subyacen dos dimensiones, se podría etiquetar amabilidad de la interacción y sinceridad. La segunda dimensión recoge, en cambio, la relación (a)simétrica de la situación de la entrevista. Los ítems atrevido/comedido y sumiso/dominante reflejan unas puntuaciones factoriales elevadas. Este factor determina la dominación en la entrevista. 
TABLA 8

Análisis de componentes principales del comportamiento de cooperación de los encuestados $(\mathbf{N}=596)$

\begin{tabular}{lcr}
\hline ftem: «El encuestado...* & Factor $\mathbf{1}$ & Factor 2 \\
\hline Respuesta contradictoria/coherente &, 66708 &,- 08715 \\
Responde con poca/mucha sinceridad &, 71933 &, 00958 \\
Tiene un carácter cerrado/abierto &, 75120 &,- 04374 \\
Es grosero/amable &, 75494 &, 27412 \\
Parece una persona antipática/simpática &, 82910 &, 09896 \\
Es callado/hablador &, 62547 &,- 30748 \\
Ha sido díficil/fácil de entrevistar &, 78810 &, 13547 \\
Tuvo una actitud recelosa/despreocupada &, 81407 &, 05223 \\
Ha sido sumiso/dominante &, 14033 &,- 83218 \\
Ha sido atrevido/comedido &, 21762 &, 78589 \\
\hline
\end{tabular}

\subsection{Tipología según la motivación de respuesta del encuestado y el modo de interacción}

La solución elegida con el análisis de conglomerados divide la muestra en tres grupos (ver cuadro 9):

Cluster A. (Motivación alta) Con casi la mitad de las entrevistas es el segmento más cuantioso y recibe las respuestas más positivas, excepto en el ítem ha sido sumiso/dominante, que refleja una diferencias mínimas respecto a los otros dos grupos.

Cluster B. (Motivación media) A él pertenecen el 38\% de las valoraciones de las entrevistas, por parte del encuestador, obteniendo una puntuaciones medias algo inferiores que el cluster $\mathrm{A}$, pero en la mayoría de las preguntas todavía por encima de la media.

Cluster C. (Motivación baja) Sólo el 13\% de las entrevistas valoradas pertenecen a este grupo, reflejando un comportamiento algo dispar, aunque las medias son más bajas que en los otros dos grupos, excepto en el ítem ha sido atrevido/comedido. A pesar de que en cuatro respuestas hay una percepción negativa de la motivación para contestar (es callado/hablador, tiene un carácter cerrado/abierto, tiene una actitud recelosaldespreocupada y ha sido difícilfácil de entrevistar), no se puede deducir que las entrevistas hayan carecido de estímulos, ya que el resto de los ítems reflejan unas puntuaciones superiores a la media.

Analizando simultáneamente los tres clusters, se observa que las respuestas ha sido sumiso/dominante y ha sido atrevido/comedido reflejan un comportamiento distinto al resto de los ítems (ver cuadro 9), coincidiendo estas categorías con lo que se ha definido en el análisis factorial precedente, la dominación en la 
entrevista. Por lo tanto, esta dimensión induce a una indefinición a la hora de establecer una tipología sobre la motivación de respuesta y el modo de interacción social.

TABLA 9

Tipología de la motivación de la respuesta

\begin{tabular}{|c|c|c|c|c|}
\hline f́tem: «El encuestado...» & $\begin{array}{c}\text { Total } \\
(\mathrm{N}=595) \\
100 \%\end{array}$ & $\begin{array}{c}\text { Cluster A } \\
(\mathrm{N}=293) \\
49,2 \%\end{array}$ & $\begin{array}{c}\text { Cluster B } \\
(\mathbf{N}=\mathbf{2 2 5}) \\
\mathbf{3 7 , 8 \%}\end{array}$ & $\begin{array}{c}\text { Cluster C } \\
(\mathbf{N}=\mathbf{7 7}) \\
13,0 \%\end{array}$ \\
\hline Responde contradictoria/coherente & 7,60 & 8,68 & 6,87 & 5,64 \\
\hline Responde con poca/mucha sinceridad & 8,18 & 9,11 & 7,68 & 6,10 \\
\hline Tiene un carácter cerrado/abierto & 6,92 & 8,32 & 6,16 & 3,81 \\
\hline Es grosero/amable & 8,28 & 9,37 & 7,48 & 6.43 \\
\hline Parece persona antipática/simpática & 7,89 & 9,02 & 7,25 & 5,44 \\
\hline Es callado/hablador & 6,19 & 7,19 & 5,84 & 3,40 \\
\hline Ha sido díficil/fácil de entrevistar & 7,79 & 9,20 & 7,10 & 4,65 \\
\hline Actitud recelosa/despreocupada & 7,45 & 8,98 & 6,57 & 4,18 \\
\hline Ha sido sumiso/dominante & 5,51 & 5,55 & 5,56 & 5,21 \\
\hline Ha sido atrevido/comedido & 6,74 & 7,27 & 6,08 & 6,68 \\
\hline
\end{tabular}

\section{EL AMBIENTE DURANTE LA ENTREVISTA}

\subsection{Descripción de las variables}

Para determinar el ambiente durante la entrevista se recurrió a 16 ítems. El entrevistado tenía que valorar si:

a) podía decir lo que pensaba,

b) el ambiente era tenso o relajado,

c) tenía o no tiempo para reflexionar sobre las preguntas,

d) desde el principio de la entrevista tenía buen ánimo,

e) inicialmente no quería hacer la entrevist, y

f) al final de la entrevista tenía un buen/mal estado de ánimo.

Por otro lado, el entrevistador tenía que evaluar el conjunto de la situación social de la entrevista, contestando a las preguntas si:

a) se sentía un espía que quería saber secretos,

b) se sentía como un representante de una institución pública que quiere unos datos,

c) un simpático desconocido con el que se puede mantener una conversación agradable, 
d) una persona a la que se le puede confiar los problemas,

e) un/a hombre/mujer al/a la que se le ayuda a hacer su trabajo, y

f) una novedad que rompe la rutina diaria.

También ha tenido que indicar el ambiente y el humor del entrevistado, tanto al principio como al final de la entrevista.

En primer lugar, hay que hacer una aclaración metodológica respecto a los dos tamaños muestrales de la tabla 10.1. Los entrevistadores se han autoaplicado 597 cuestionarios una vez realizada la entrevista principial. El número de los cuestionarios cumplimentados por los entrevistados es de 310, aproximadamente. La participación es baja dado que se trata de una colaboración voluntaria posterior de la entrevista, mediante envío del cuestionario por correo, o recogida en un sobre cerrado. La cuota de respuesta es del $55 \%$ de la muestra inicial, que, de todas formas, sigue siendo un resultado más que aceptable.

\section{TABLA 10.1}

\section{Estimación del ambiente de la entrevista}

\begin{tabular}{llll}
\hline $\begin{array}{l}\text { «El encuestador declara sentirse como...» } \\
\text { (escala: 1=si coincide, 10=no coincide) }\end{array}$ & Media & S.D. & (N) \\
\hline Un espía & 8,30 & 2,03 & 597 \\
Un representante de una institución pública & 3,95 & 2,77 & 596 \\
Un simpático desconocido & 5,36 & 2,62 & 596 \\
Una persona a la que se le confia los problemas & 6,73 & 2,44 & 597 \\
Una pobre persona a la que se le ayuda hacer el trabajo & 5,40 & 2,55 & 597 \\
Una novedad que rompe la rutina & 5,26 & 2,64 & 597 \\
\hline «El encuestador percibe... " & & & \\
\hline Mal/buen ambiente al principio de la entrevista & 7,99 & 1,96 & 597 \\
Mal/buen ambiente al final de la entrevista & 8,34 & 1,78 & 596 \\
Mal/buen humor del entrevistado al principio & 7,98 & 1,72 & 597 \\
Mal/buen humor del entrevistado al final de la entrevista & 8,16 & 1,74 & 597 \\
\hline «El encuestado declara que...» & & & \\
\hline No podía/podía decir lo que pensaba & & & \\
Había un ambiente tenso/relajado & 8,83 & 1,72 & 306 \\
No/si tenía tiempo para reflexionar sobre las preguntas & 8,12 & 2,11 & 309 \\
Al principio si/no quería hacer la entrevista & 8,15 & 2,27 & 308 \\
Al principio de la entrevista tenía mal/buen ánimo & 7,85 & 2,18 & 310 \\
Al final de la entrevista tenía malo/buen ánimo & 8,65 & 1,51 & 309 \\
\hline
\end{tabular}

En primer lugar hay que observar -ver tabla 10.1- la ambivalencia del encuestador, resultado de un conflicto de roles (Scholl). En tres de los items de autovaloración («simpático desconocido», «pobre persona» y «novedad») no se 
puede definir, de forma que se autopuntúa con 5. Quizás porque se ve como representante de una institución, aunque no se considera un espía, sabe que nunca se va a confiar en él, por muy positivamente que le vea el entrevistado o que él mismo perciba la situación de la entrevista.

En otro orden de cosas, si se observan las medias, hay que destacar que la valoración del ambiente de la entrevista es casi igual de positiva para los entrevistados que para los entrevistadores, observándose de esta forma un coincidencia valorativa entre los dos sujetos que participan en la interacción social.

Otro dato curioso es que las percepciones al final de la entrevista son mejores que al principio, y tanto en el encuestador como en el encuestado -una especie de «efecto socrático», utilizando muy libremente una expresión tomada del campo de la metodología de las encuestas panel ${ }^{5}$. Se desmienten argumentos del tipo «las entrevistas empiezan bien, pero luego se crea mal ambiente por la impaciencia del entrevistador, por la duración de la entrevista, etc.». Parece ser que la dificultad se ubica más bien en el contacto inicial de la persona a entrevistar, pero una vez superada esta barrera, la comunicación verbal y no verbal de la interacción social de la situación de la entrevista es buena.

En este punto puede ser interesante contrastar estos resultados con los que obtiene Scholl (1993) en Alemania. La comparación se presenta en la tabla 10.2.

En ambos países el entrevistador percibe un mejor humor al final de la entrevista que al principio. Lo más significativo son las diferencias que se observan en la autopercepción de los encuestados. Los alemanes apenas cambiaron de humor -pasan sólo de 8.40 a 8.58- mientras que los españoles mejoraron considerablemente -pasamos de 7.85 a 8.65. El humor de los encuestados españoles al empezar la entrevista es peor que el los alemanes, pero al final es mejor que el de éstos últimos.

TABLA 10.2

Valoración del humor o ánimo del entrevistado por el entrevistador y por el entrevistado, al principio y al final de la entrevista.

\begin{tabular}{|c|c|c|c|}
\hline & & ESPAÑ A & ALEMANIA \\
\hline \multirow{2}{*}{ AL PRINCIPIO DE LA ENTREVISTA } & $\begin{array}{l}\text { a) encuestador } \\
\text { b) encuestado }\end{array}$ & $\begin{array}{l}7.98 \\
7.85\end{array}$ & $\begin{array}{l}6.99 \\
8.40\end{array}$ \\
\hline & a) / b) & 1.01 & 0.83 \\
\hline \multirow{2}{*}{ AL FINAL DE LA ENTREVISTA } & $\begin{array}{l}\text { a) encuestador } \\
\text { b) encuestado }\end{array}$ & $\begin{array}{l}8.16 \\
8.65\end{array}$ & $\begin{array}{l}7.42 \\
8.58\end{array}$ \\
\hline & a) $/$ b) & 0.94 & 0.86 \\
\hline
\end{tabular}

5 Jagodzinski/Kühnel/Schmidt (1987) han estudiado la consistencia en estudios de panel de actitudes. La consistencia aumenta considerablemente en olas sucesivas, especialmente hasta la tercera. Luego parece producirse algo así como rendimientos decrecientes. Ese aumento inicial de la consistencia es lo que se ha bautizado como «efecto socrático». Aquí utilizamos la etiqueta para designar el cambio de las imágenes recíprocas debida a la interacción. ¿Quizá debiéramos hablar, mejor, de efecto «simpatía»? 
Pero lo más interesante es que en España se observa una menor disonancia -0 , si se prefiere- una mayor concordancia entre la percepción del entrevistador y la autopercepción del entrevistado, sobre todo al principio de la entrevista. En este primer momento, en España la razón de las puntuaciones de ambos actores es de 1 , mientras que en Alemania es de 0.83 . Después de la entrevista se produce un aumento de la disonancia en España -la razón es ahora de 0.94-, mientras que la de Alemania permanece estable -0.86. El motivo es, como apuntábamos, que en España mejora extraordinariamente la autopercepción favorable del encuestado -el «efecto socrático» o, mejor, «simpatía».

\section{PERCEPCIÓN POLÍTICA DEL ENCUESTADOR POR EL ENCUESTADO}

\subsection{Descripción de las variables}

Un aspecto concreto, de mucho interés, es el referido a los juicios políticos que se forman los actores sociales durante la entrevista. Independientemente de la ideología política o la intención de voto, se han planteado a los encuestados cuestiones específicas que han podido tener en cuenta para formar un juicio de la actitud política de los entrevistadores. Para medir esta supuesta influencia se ha utilizado, una vez más, la escala de 10 puntos, en la cual el valor 1 significa que no se tiene nada en cuenta la cuestión, y el valor 10 , que lo tiene muy en cuenta. Pues bien, como muestra la tabla 11 , todos los ítems se inclinan hacia la izquierda. Asi pues, parece que el encuestado no suele tener en cuenta los distintos aspectos de la interacción social de la entrevista (la forma de preguntar las preguntas, los comentarios, el que fuera una mujer o un hombre, etc.) a la hora de valorar la actitud política del encuestador.

TABLA 11

Indicadores de posicionamiento político del encuestador

\begin{tabular}{lccc}
\hline «El encuestado ha tenido muy/nada en cuenta...* & Media & S.D. & (N) \\
\hline La forma de plantear las preguntas el encuestador & 3,83 & 3,12 & 254 \\
Los comentarios del encuestador & 3,86 & 3,13 & 251 \\
La forma de hablar del encuestador & 4,25 & 3,39 & 254 \\
La forma de comportarse del encuestador & 4,40 & 3,47 & 255 \\
El aspecto físico del encuestador & 4,14 & 3,33 & 252 \\
La forma en que iba vestido del encuestador & 4,04 & 3,33 & 254 \\
La edad del encuestador & 3,70 & 3,05 & 254 \\
Los gestos del encuestador & 3,50 & 3,07 & 252 \\
El que encuestador fuera hombre o mujer & 2,92 & 2,81 & 252 \\
La reacción del encuestador a mis respuestas & 3,92 & 3,27 & 257 \\
\hline
\end{tabular}




\subsection{Dimensiones de las variables}

Como resultado del análisis factorial se obtiene de nuevo una única dimensión, que explica el $73 \%$ de la varizanza de los 10 items originales (ver tabla 12). Los pesos factoriales son elevados en todos las variables, sin que sea posible establecer diferencias entre las características personales del encuestador (edad, género, aspecto físico, la forma que iba vestido) y los indicadores relacionados directamente con la interacción (forma de plantear las preguntas, los comentarios, la reacción a las respuestas, etc.).

\section{TABLA 12}

Análisis de componentes principales de los factores que influyen en la percepción de la actitud política del encuestador $(\mathbf{N}=\mathbf{2 5 1})$

\begin{tabular}{lc}
\hline «El encuestado ha tenido muy/nada en cuenta...» & Factor 1 \\
\hline La forma de plantear las preguntas el encuestador &, 82108 \\
Los comentarios del encuestador &, 81804 \\
La forma de hablar del encuestador &, 90256 \\
La forma de comportarse del encuestador &, 91221 \\
El aspecto físico del encuestador &, 87255 \\
La forma en que iba vestido del encuestador &, 86422 \\
La edad del encuestador &, 85901 \\
Los gestos del encuestador &, 88994 \\
El que encuestador fuera hombre o mujer &, 79866 \\
La reacción del encuestador a mis respuestas &, 78849 \\
\hline
\end{tabular}

\subsection{Tipología}

Con la ayuda del análisis de conglomerados hemos obtenido dos clusters de tamaño similar y bien diferenciados (ver tabla 13). El cluster $\mathbf{A}$, compuesto por el 59\% de la muestra válida de los encuestados, no ha tenido casi nada en cuenta los distintos factores que explican la actitud política del encuestador. En este conglomerado el encuestador es ideológicamente neutro. En cambio, el cluster B, al que pertenecen el $41 \%$ de los encuestados, puntúa por encima de la media de la escala en todas las variables, excepto en el item que hace referencia al sexo del encuestador. Se trata de un tipo de encuestado atento, que probablemente pudiera explicitar sus deducciones sobre la actitud política del encuestador de una forma racional y lógica. Para este conglomerado el encuestador es ideológicamente «expresivo». 
TABLA 13

Tipología del encuestado, según su percepción de la actitud política del encuestador

\begin{tabular}{lccc}
\hline «El encuestado ha tenido muy/nada en cuenta...» & $\begin{array}{c}\text { Total } \\
(\mathbf{N = 2 4 3 )} \\
\mathbf{1 0 0 \%}\end{array}$ & $\begin{array}{c}\text { Cluster A } \\
(\mathbf{N = 1 4 3 )} \\
\mathbf{5 8 , 9 \%}\end{array}$ & $\begin{array}{c}\text { Cluster B } \\
\mathbf{( N = 1 0 0 )} \\
\mathbf{4 1 , 1 \%}\end{array}$ \\
\hline La forma de plantear las preguntas el encuestador & 3,79 & 1,91 & 6,47 \\
Los comentarios del encuestador & 3,82 & 1,89 & 6,59 \\
La forma de hablar del encuestador & 4,11 & 1,85 & 7,34 \\
La forma de comportarse del encuestador & 4,24 & 1,94 & 7,53 \\
El aspecto físico del encuestador & 3,99 & 2,01 & 6,82 \\
La forma en que iba vestido del encuestador & 3,90 & 1,96 & 6,68 \\
La edad del encuestador & 3,67 & 1,83 & 6,30 \\
Los gestos del encuestador & 3,43 & 1,49 & 6,21 \\
El que encuestador fuera hombre o mujer & 2,89 & 1,25 & 5,23 \\
La reacción del encuestador a mis respuestas & 3,84 & 1,93 & 6,57 \\
\hline
\end{tabular}

\section{CONCLUSIONES}

Las percepciones recíprocas del entrevistador y el entrevistado que acabamos de ver se asemejan a las que obtuviera Scholl (1993) en Alemania.

La percepción del encuestado por el encuestador es muy positiva. Considera que es cognitivamente competente, aunque no siempre esté muy interesado por la encuesta. Al menos la mitad de los entrevistados son percibidos como altamente competentes por el entrevistador.

El entrevistador también percibe normalmente una actitud de cooperación en el encuestado. En torno al $70 \%$ de los encuestados están en buena disposición. Según el encuestador son fáciles de entrevistar.

Al entrevistador tampoco se le escapan características de la interacción, como la propensión de algunos encuestados a contestar teniendo en cuenta la deseabilidad social de la respuestas. Nota que muchos encuestados se esfuerzan por quedar bien y son sumisos. Por lo demás, parece que la entrevista de encuesta se aproximase a una «situación ideal de diálogo». Y es que la valoración del ambiente de la entrevista por las dos partes, del entrevistador y del entrevistado, es coincidente. Los dos perciben un ambiente positivo. Además, parece darse un efecto de simpatía, en el sentido de que con el diálogo mejora la interacción. La valoración de la situación por ambas partes es mejor después de la entrevista.

Finalmente, por parte del entrevistador, despunta una tensión de roles que produce una identidad difusa. El hecho es que aunque percibe una actitud exquisitamente amable del encuestado y una situación favorable a la interacción, sabe que nunca se va a confiar del todo en él.

En cuanto a la percepción del encuestador por el encuestado, la mitad de estos declaran haberse fijado en algún rasgo externo de aquel para intentar 
encasillarlo ideológicamente. Fundamentalmente se tiene en cuenta la forma de comportarse del encuestador. Pero, de todas formas, es una percepción muy difusa $-o$ al menos, así se proclama.

Se puede concluir que se confirman los resultados de Scholl (1993) sobre Alemania: también en España encontramos una actitud deferente por ambas partes. La meta-encuesta parece introducir este sesgo en la valoración de la encuesta, con el agravante además de que en España parece darse una connivencia entre el entrevistador y el entrevistado más intensa de la que se daría en Alemania.

Queda abierta la cuestión de si en España se da o no el efecto de la interacción entrevistador-entrevistado sobre las respuestas del entrevistado -en Alemania sucede que no ${ }^{6}$. Pero lo que venimos de subrayar -la deferencia de ambas partes- hace sospechar que, de existir ese efecto, será difícil de medir recurriendo a la metodología de la encuesta sobre la encuesta.

\section{REFERENCIAS BIBLIOGRÁFICAS}

Alvira, F./MARTínEz, E. (1985): «El efecto de los entrevistadores sobre las respuestas a los entrevistados», Revista Española de Investigaciones Sociológicas, 29: 219-256.

BrIGGS, C. (1989): Learning How to Ask. A Sociolinguistic Appraisal of the Role of the Interview in Social Science Research, Cambrige U.P., Cambridge.

DiJKSTRA, W. (1987): 'Interviewing style and respondent behaviour', Sociological Methods and Research, 16(2): 309-334.

EsBENSEN, F./MENARD, S. (1991): «Interviewer-related measurement error in attitudinal research», Quality \& Quantity, 25(1): 151-165.

EssER, H. (1975): Soziale Regelmässigkeiten des Befragtenverhaltens, Hain, Meisenheim am Glan.

- (1986): 'Können Befragte lügen? Zum Konzept des 'wahren Wertes' im Rahmen der handlungstheoretischen Erklärung von Situationseinflüssen bei der Befragung', Kölner Zeitschrift für Soziologie und Sozialpsychologie, 38 (2): 314-336.

- (1993): 'Response set: habit, frame or rational choice', en D. Krebs/ P. Schmidt (Eds.): New Directions in Attitude Measurement, De Gruyter, Berlin/ New York, pp. 293-313.

García Ferrando, M./García, M. (1976): 'Las encuestas a encuesta', Revista Española de Opinión Pública, 45, 266-292.

GOYDER, J. (1987): The Silent Minority. Nonrespondents on Sample Surveys, Polity Press, Oxford.

HARTMANN, P. (1991): Wunsch und Wirklichkeit. Theorie und Empirie soziales Erwünschheit, Deutscher -UniversitätsVerlag, Vieweg.

JAGODZINSSKI, W./KUHNEL, S./SCHMIDT, P. (1987): 'Is there a socratic effect in nonexperimental panel studies?', Sociological Methods and Research, 15(3): 415-443.

JUSTEL, M. (1981): 'Las encuestas a encuesta, de nuevo', Revista Española de Investigaciones Sociologicas, 13: 155-181.

MishleR, E. (1986): Research Interviewing. Context and Narrative, Harvard UP, Cambridge.

\footnotetext{
${ }^{6}$ Queda para un posterior trabajo la contrastación de la hipótesis de la reactividad, es decir, del nexo causal entre las imágenes recíprocas y el patrón de respuestas.
} 
NoYA, J. (1998): Los efectos de contexto en el cuestionario, Depto. Sociología II (UNED), trabajo inédito.

Pawson, R. (1996): 'Theorizing the interview', British Journal of Sociology, 47.

Procter, I./PADfield, M. (1998): 'The effect of the interview on the interviewee', Social Research Methodology, 1(2): 123-136.

REINECKE, J. (1991): Interviewer- und Befragtenverhalten. Theoretische Ansätze und methodische Konzepte, Westdeutscher Verlag, Opladen.

REINECKE, J./SCHMIDT, P. (1993): 'Explaining interviewer effects and respondent behavior: theoretical models and empirical analysis', Quality \& Quantity, 27 (2): 219-247.

Scholl, A. (1993): Die Befragung als Kommunikationsituation. Zur Reaktivität im Forschungsinterview, Wesdeutscher Verlag, Opladen.

STEINERT, M. (1984): 'Das Interview als soziale Interaktion', en M. Meulemann/ K. Reuband (Hrsg.): Soziale Realität im Interview, Campus, Frankfurt, pp. 17-59.

\title{
RESUMEN
}

En la hipótesis de la reactividad se postula que la interacción social que se produce entre el entrevistador y el entrevistado en la situación de la entrevista de encuesta va a influir en las respuestas del entrevistado. Un paso previo es establecer las imágenes recíprocas que tienen el entrevistador y el entrevistado. Las cogniciones, actitudes y emociones que se activan durante la entrevista en reacción a las cogniciones, actitudes y emociones que se perciben en el otro participante pueden conocerse a posteriori mediante una encuesta sobre la encuesta realizada a ambas partes, al encuestador sobre el entrevistado y al entrevistado sobre el encuestador. En el trabajo se exponen los resultados que se obtienen en España de la réplica de este diseño metodológico seguido por Scholl en Alemania.

\begin{abstract}
In the reactivity hypothesis the idea is posed that interaction between the interviewer and the interviewed in surveys inpinches upon the answers given by the latter. In order to test this hypothesis, reciprocal views of the interviewer and the interviewed must be known. Information about them can be obtained from a second survey, a survey on the survey. In it, the interviewer is asked about the interviewed, and viceversa. In this paper, results produced in Spain with this methodology are presented and compared to those obtained in Germany with an identical design.
\end{abstract}

